\title{
Aerosol Delivery and Humidification With the Boussignac Continuous Positive Airway Pressure Device
}

\author{
Arnaud W Thille MD PhD, Jean-François Bertholon MD PhD, Marie-Hélène Becquemin MD PhD, \\ Monique Roy PharmD, Aissam Lyazidi PhD, François Lellouche MD PhD, Esther Pertusini MD, \\ Georges Boussignac MD, Bernard Maître MD PhD, and Laurent Brochard MD
}

\begin{abstract}
BACKGROUND: A simple method for effective bronchodilator aerosol delivery while administering continuing continuous positive airway pressure (CPAP) would be useful in patients with severe bronchial obstruction. OBJECTIVE: To assess the effectiveness of bronchodilator aerosol delivery during CPAP generated by the Boussignac CPAP system and its optimal humidification system. METHODS: First we assessed the relationship between flow and pressure generated in the mask with the Boussignac CPAP system. Next we measured the inspired-gas humidity during CPAP, with several humidification strategies, in 9 healthy volunteers. We then measured the bronchodilator aerosol particle size during CPAP, with and without heat-and-moisture exchanger, in a bench study. Finally, in 7 patients with acute respiratory failure and airway obstruction, we measured work of breathing and gas exchange after a $\boldsymbol{\beta}_{2}$-agonist bronchodilator aerosol (terbutaline) delivered during CPAP or via standard nebulization. RESULTS: Optimal humidity was obtained only with the heat-and-moisture exchanger or heated humidifier. The heat-and-moisture exchanger had no influence on bronchodilator aerosol particle size. Work of breathing decreased similarly after bronchodilator via either standard nebulization or CPAP, but $\mathbf{P}_{\mathrm{aO}}$ increased significantly only after CPAP aerosol delivery. CONCLUSIONS: CPAP bronchodilator delivery decreases the work of breathing as effectively as does standard nebulization, but produces a greater oxygenation improvement in patients with airway obstruction. To optimize airway humidification, a heat-and-moisture exchanger could be used with the Boussignac CPAP system, without modifying aerosol delivery. Key words: continuous positive airway pressure; CPAP; work of breathing; aerosol therapy; $\beta_{2}$-agonist; bronchodilator; heat-and-moisture exchanger; heated humidifier. [Respir Care 2011;56(10):1526-1532. (C) 2011 Daedalus Enterprises]
\end{abstract}

\footnotetext{
Drs Thille, Lyazidi, Lellouche, Pertusini, Boussignac, and Brochard are affiliated with the Medical Intensive Care Unit, Assistance PubliqueHôpitaux de Paris, Henri Mondor Hospital, University of Paris Est, Créteil, France. Dr Bertholon is affiliated with the Department of Respiratory Physiology, Assistance Publique-Hôpitaux de Paris, Saint-Antoine Hospital, Paris, Pierre et Marie Curie University, Paris, France. Dr Becquemin is affiliated with the Service d'Explorations Fonctionnelles Respiratoires, Assistance Publique-Hôpitaux de Paris, Pitié-Salpêtrière Hospital, Paris, France. Dr Roy is affiliated with the Laboratoire de Granulométrie et de Dépôt des Aérosols, Assistance Publique-Hôpitaux de Paris, Pitié-Salpêtrière Hospital, Paris, France. Dr Maître is affiliated with the Department of Pulmonology, Assistance Publique-Hôpitaux de Paris, Henri Mondor Hospital, Créteil Intercommunal Hospital, University of Paris Est, Créteil, Créteil, France.
}

\begin{abstract}
This study was partly supported by a joint grant from the Bourse Commune de la Société de Réanimation de Langue Française and the Société de Pneumologie de Langue Française.

Dr Boussignac is the inventor of the Boussignac CPAP device and receives royalties from sales of the device and is a consultant for Vygon, France. The other authors have disclosed no conflicts of interest.

Correspondence: Arnaud W Thille MD PhD, Réanimation Médicale, Hôpital Henri Mondor, 51 Avenue du Maréchal de Lattre de Tassigny, 94010 Créteil, France. E-mail: arnaud.thille@hmn.aphp.fr.
\end{abstract}

DOI: $10.4187 /$ respcare. 00847 


\section{Aerosol Delivery and Humidification With the Boussignac CPAP Device}

\section{Introduction}

Continuous positive airway pressure (CPAP) via face mask is effective in several forms of acute respiratory failure. CPAP hastened recovery and decreased the need for intubation in patients with acute pulmonary edema, ${ }^{1,2}$ avoided re-intubation in hypoxemic postoperative patients, ${ }^{3}$ and decreased the work of breathing (WOB) and dyspnea in patients with COPD. ${ }^{4,5}$ During mechanical ventilation of COPD patients with dynamic hyperinflation, external PEEP diminished patient effort for inspiration by decreasing intrinsic PEEP. ${ }^{6-8}$

CPAP can be generated with the Boussignac CPAP system (Vygon, Écouen, France), which is a small disposable plastic cylinder that fits on the mask and generates positive pressure by accelerating a flow of air and/or oxygen. In patients with acute pulmonary edema treated in the emergency room, the Boussignac CPAP device provided benefits similar to those of pressure support ventilation (PSV) delivered by a ventilator. ${ }^{9}$

Inhaled $\beta_{2}$-agonists and anticholinergic bronchodilators are the first-line treatment of bronchospasm during asthma or COPD exacerbation. ${ }^{10,11}$ In patients with severe bronchospasm these agents are usually delivered via pneumatic nebulizer, with a gas flow of about $6 \mathrm{~L} / \mathrm{min} .{ }^{12}$ Pneumatic nebulizer is as efficient as delivery via metered-dose inhaler, ${ }^{13}$ and more efficient and better tolerated than intravenous administration. ${ }^{14}$ However, in patients requiring CPAP, a method for delivering bronchodilator aerosol while applying CPAP would be useful.

Few studies have evaluated aerosol delivery during CPAP ${ }^{15,16}$ or PSV. ${ }^{17-20}$ Some studies found substantial aerosol loss, possibly related to particle impaction in the mask due to the high flow required to generate CPAP. ${ }^{16}$ Other studies found that aerosol delivery with CPAP was associated with better lung aerosol deposition ${ }^{18}$ or better clinical outcomes. ${ }^{15,17}$ We conducted this physiological study to evaluate the effectiveness of aerosol delivery during CPAP. We searched for the optimal humidification strategy during CPAP, and in patients with airway obstruction we measured patient inspiratory effort before and after $\beta_{2}$-agonist administered during CPAP versus during spontaneous ventilation.

\section{Methods}

This study was approved by the institutional review board of Henri Mondor Hospital, and all subjects gave written informed consent before study inclusion. The study was conducted in the research laboratories of Pitié-Salpêtrière Hospital and Henri Mondor Hospital, and in the medical intensive care unit of Henri Mondor Hospital. We tested the Boussignac CPAP device (Fig. 1), which uses the incoming flow of gas to generate turbulence that creates a "virtual valve" at the mask opening. The gas (air or $\mathrm{O}_{2}$ ) entering through a distal connector at the open end of the device is accelerated in 4

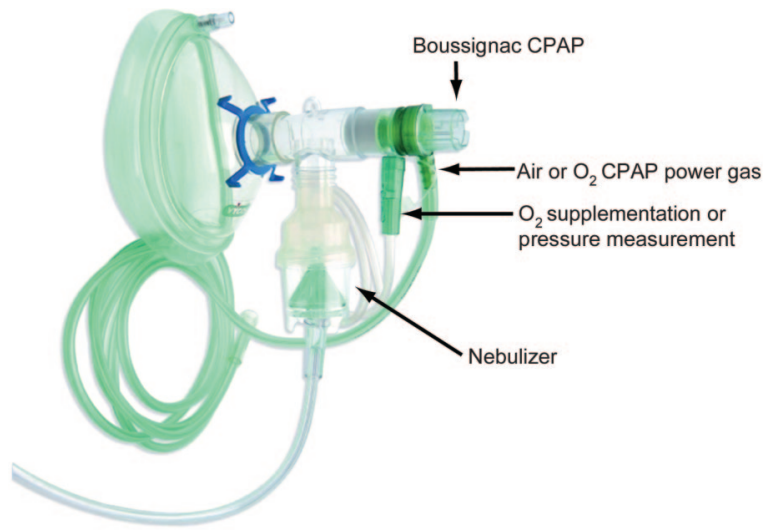

Fig. 1. The Boussignac continuous positive airway pressure (CPAP) is a small plastic cylinder that attaches to a face mask. The distal connector at the device's open end connects to the driving gas (air or $\mathrm{O}_{2}$ ), and the proximal connector on the patient side allows either oxygen supplementation or mask-pressure measurement.

very small holes around the open-ended cylinder, which generates a positive pressure in the mask. A proximal connector on the patient side of the cylinder allows for either oxygen supplementation, if the source gas is air, or mask-pressure monitoring with a manometer.

\section{Pressure Generated by the Boussignac CPAP Device}

To evaluate the relationship between the gas flow in the device and the pressure generated in the mask, we recorded the pressure in the mask at several flows. From a wall source, compressed gas was delivered from a rotameter (Prolabo, Fontenay-sous-Bois, France) to the distal connector, at flows of 0 to $35 \mathrm{~L} / \mathrm{min}$. Through the proximal connector we measured pressure in the mask with a manometer (KI16, Vygon, Écouen, France), at pressures of 0 to $25 \mathrm{~cm} \mathrm{H}_{2} \mathrm{O}$. We measured the pressure generated by the CPAP device without ventilation and during inspiration and expiration, with a manually operated pump connected to the CPAP device by a hose, and set to a tidal volume of $500 \mathrm{~mL}$ and a respiratory rate of 12 breaths $/ \mathrm{min}$.

\section{Gas Hygrometry}

We used a previously described psychrometric method ${ }^{21}$ to measure the absolute humidity of the inspired gas. We tested 4 humidification strategies at room temperature $\left(22^{\circ} \mathrm{C}\right)$ in 9 healthy volunteers receiving CPAP at a constant $7.5 \mathrm{~cm} \mathrm{H}_{2} \mathrm{O}$, during: no humidification; cold water humidification in 1 or 2 connectors of the CPAP device; heat-and-moisture exchanger (Humid-Vent, Hudson RCI, Temecula, California) (28 mL dead space) placed between the mask and the CPAP device; and heated humidifier (MR850, Fisher \& Paykel, Auckland, New Zealand) with 


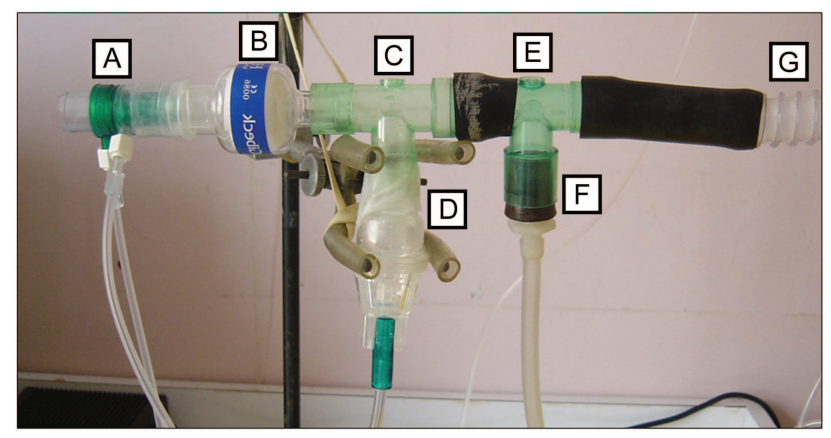

Fig. 2. Setup for aerosol particle size measurement. A: Boussignac continuous positive airway pressure (CPAP) device, connected to a compressed air source. B: Heat-and-moisture exchanger. C: Tpiece. D: Nebulizer. E: T-piece. F: Laser diffraction particle sizer and counter. G: Ventilator circuit, leading to a pump.

an additional gas source at $7 \mathrm{~L} / \mathrm{min}$ and $12 \mathrm{~L} / \mathrm{min}$. This experiment was performed without nebulization.

\section{Aerosol Particle Size}

We measured the aerosol particle size distribution of the terbutaline aerosol during CPAP before and after placing a heat-and-moisture exchanger between the CPAP device and the nebulizer. We used a CPAP of $10 \mathrm{~cm} \mathrm{H}_{2} \mathrm{O}$ and simulated physiologic ventilation by producing expired air that was water-saturated at $37^{\circ} \mathrm{C}$, a $1,000-\mathrm{mL}$ tidal volume, and a respiratory rate of 12 breaths $/ \mathrm{min}$. The setup was composed of a pump that simulated a patient, a T-piece to sample aerosol, a nebulizer, a heat-and-moisture exchanger, and the CPAP device (Fig. 2). The jet nebulizer (LC Sprint, Pari, Starnberg, Germany) was attached to the open end of the CPAP device with a T-piece, and run with a flow $6 \mathrm{~L} / \mathrm{min}$. The LC Sprint nebulizer delivers aerosol with a mass median aerodynamic diameter of $3.3 \mu \mathrm{m}$, and $70 \%$ of the particles are $<5 \mu \mathrm{m}$. We sampled the aerosol at the T-piece and measured the aerosol with a laser diffraction particle sizer and counter (LAP 320, Topas, Dresden, Germany).

\section{Bronchodilator Delivery With Versus Without CPAP}

We screened patients admitted for hypercapnic acute respiratory failure who required noninvasive ventilation (NIV). We included patients with persistent hypercapnia $\left(\mathrm{P}_{\mathrm{aCO}_{2}}>45 \mathrm{~mm} \mathrm{Hg}\right)$ that suggested chronic pulmonary disease. We excluded patients with cardiac pulmonary edema, acute asthma, or any risk factor related to placement of an esophageal balloon (eg, thrombocytopenia or gastrointestinal bleeding). We studied the included patients when they had been in stabilized condition for 24 hours after weaning from NIV.

We compared the respiratory effect of a $\beta_{2}$-agonist (terbutaline $5 \mathrm{mg}$ ) delivered via standard nebulization or via $\mathrm{CPAP}$, in random order, at an interval of 3 hours, to minimize carry-over effects. The bronchoprotective effect of $\beta_{2}$-agonists is maximal at $90 \mathrm{~min}$, followed by a sharp drop 3 hours after inhalation, and complete elimination at 6 hours. ${ }^{22}$ Standard nebulization was via jet nebulizer (Cirrus, Intersurgical, United Kingdom, mass median aerodynamic diameter $2.7 \mu \mathrm{m}$, $70 \%$ of particles $<5 \mu \mathrm{m}$ ) and face mask. The nebulizer was powered with compressed air during both CPAP and standard nebulization. The air flow was $6 \mathrm{~L} / \mathrm{min}$ during standard nebulization, and $15 \mathrm{~L} / \mathrm{min}$ during CPAP, to maintain a minimum positive pressure of $5 \mathrm{~cm} \mathrm{H}_{2} \mathrm{O}$. Nebulization time and time on CPAP was 5-10 min. $\mathrm{O}_{2}$ was administered via nasal cannula during standard nebulization, and via the proximal connector during CPAP. The $\mathrm{O}_{2}$ flow was the same throughout all experiments. After nebulization, all patients received $\mathrm{O}_{2}$ via nasal cannula and underwent arterial blood gas measurements. Before and $15 \mathrm{~min}$ after each nebulization we measured variables that reflect patient effort and gas exchange.

We measured airway pressure with a differential pressure transducer (MP45, Validyne, Northridge, California, $\pm 80 \mathrm{~cm} \mathrm{H}_{2} \mathrm{O}$ ), and flow with a pneumotachograph (No. 2, Fleisch, Lausanne, Switzerland) connected to a face mask. We measured esophageal and gastric pressure with a doublelumen catheter equipped with 2 balloons (Marquat, Boissy Saint-Léger, France). Appropriate placement of the esophageal balloon was verified with an occlusion test..$^{23}$ All signals were recorded at $200 \mathrm{~Hz}$ with an analog-to-digital dataacquisition system (MP100, Biopac Systems, California). We calculated respiratory muscle energy expenditure from the esophageal pressure-time product per breath and per minute, by measuring the area under the esophageal pressure signal between the onset of inspiratory effort and the end of inspiration. This area was referred to as the chest-wall static recoil pressure-time curve relationship. ${ }^{24} \mathrm{~A}$ difference between the beginning of the negative esophageal-pressure deflection and the zero-flow point was taken as the intrinsic PEEP ${ }^{25}$ and was corrected for any abdominal pressure activity. ${ }^{26}$ We computed patient inspiratory WOB per breath from the area included between the esophageal pressure/tidal volume loop and the chest-wall relaxation curve, using the Campbell diagram, as previously described. ${ }^{8}$

\section{Statistic Analysis}

We compared the ventilatory pattern data and the patient-effort variables with the Wilcoxon test for each period, as the small number of patients required a nonparametric test. $P<.05$ was considered statistically significant.

We estimated that 15 patients would be required to detect a 20\% WOB difference between CPAP and standard nebulization. Analysis of the data from the first 7 patients found no significant WOB difference between CPAP and standard nebulization. This finding, together with the difficulties raised by performing the clinical trial, prompted us to end the trial prematurely, making it close to a feasibility study. 


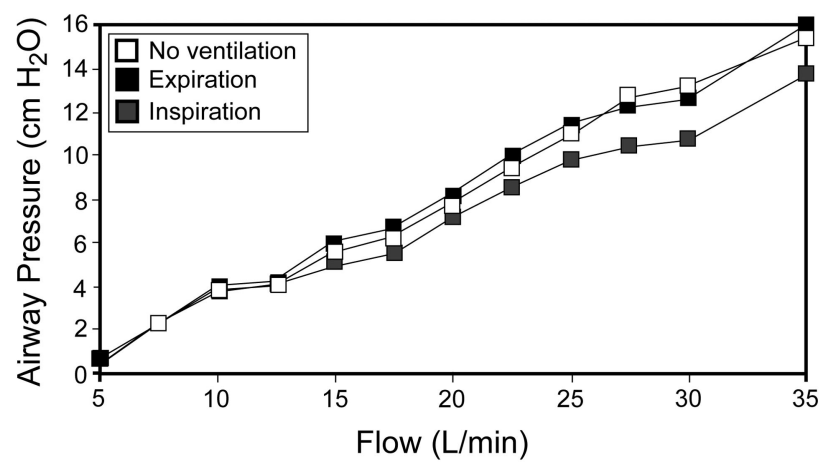

Fig. 3. Relationship between the nebulizer driving gas flow and continuous positive airway pressure (CPAP) generated in the mask, with the Boussignac CPAP system during inspiration, expiration, or without CPAP.

\section{Results}

\section{Pressure Generated by the Boussignac CPAP Device}

Figure 3 shows the relationship between the gas flow rate and the pressure generated by the Boussignac CPAP device. A flow of $15 \mathrm{~L} / \mathrm{min}$ generated a pressure of $6 \mathrm{~cm} \mathrm{H}_{2} \mathrm{O}$ during expiration and $5 \mathrm{~cm} \mathrm{H}_{2} \mathrm{O}$ during inspiration. A flow of $25 \mathrm{~L} /$ min was required to keep the pressure above $10 \mathrm{~cm} \mathrm{H}_{2} \mathrm{O}$.

\section{Gas Hygrometry}

Figure 4 shows the absolute humidity data. Mean absolute humidity without humidification was $4 \pm 1 \mathrm{mg} / \mathrm{L}$. Humidification with cold water increased absolute humidity slightly, to 7-12 $\mathrm{mg} / \mathrm{L}$. Absolute humidity greater than $25 \mathrm{mg} / \mathrm{L}$ was obtained only with the heat-and-moisture exchanger or the heated humidifier.

\section{Aerosol Particle Size With and Without Heat-and-Moisture Exchanger}

Adding a heat-and-moisture exchanger between the Boussignac CPAP device and the nebulizer had no influence on the terbutaline aerosol particle size. The median particle size diameter was similar with or without heatand-moisture exchanger $(0.8 \mu \mathrm{m})$, and the geometric standard deviation remained unchanged.

\section{Comparison of Bronchodilator Delivery by CPAP Versus Standard Nebulization}

We studied 7 patients ( 5 females and 2 males, mean age $64 \pm 17$ years) admitted to the ICU for hypercapnic acute respiratory failure (mean admission $\mathrm{P}_{\mathrm{aCO}}, 53 \pm 23 \mathrm{~mm} \mathrm{Hg}$ ) and who had been weaned off NIV for at least 24 hours (Table 1). Patient WOB showed a decrease of borderline statistical significance $(P=.06)$ after bronchodilator neb- ulization with both standard nebulization and CPAP aerosol administration (Fig. 5): $39 \pm 34 \%$ decrease after standard nebulization versus $37 \pm 39 \%$ decrease after CPAP nebulization. The $\mathrm{P}_{\mathrm{aCO}_{2}}$ changes were not different between the 2 modalities. However, $\mathrm{P}_{\mathrm{aO}}$ increased significantly more after CPAP nebulization than after standard nebulization.

\section{Discussion}

With the Boussignac CPAP device the flows required to maintain a continuous pressure of $5 \mathrm{~cm} \mathrm{H}_{2} \mathrm{O}$ or $10 \mathrm{~cm} \mathrm{H}_{2} \mathrm{O}$ were $15 \mathrm{~L} / \mathrm{min}$ and $25 \mathrm{~L} / \mathrm{min}$, respectively. Because highflow compressed gas results in low humidity, a humidification device was needed. The heat-and-moisture exchanger did not significantly affect terbutaline aerosol particle size. In a small sample of patients with airway obstruction, WOB decreased similarly with CPAP nebulization or standard nebulization. CPAP significantly improved oxygenation, compared to standard nebulization with the same oxygen flow.

\section{Influence of CPAP and Heat-and-Moisture Exchanger on Aerosol Delivery}

The gas flow rate used to drive the nebulizer has a major influence on aerosol delivery, ${ }^{27}$ and the high flow rate during CPAP could decrease aerosol delivery. ${ }^{16} \mathrm{~A}$ bench study found a marked decrease in bronchodilator aerosol deposition in the face mask with nebulization during classical CPAP (10 $\left.\mathrm{cm} \mathrm{H}_{2} \mathrm{O}\right)$, which suggests a reduction in aerosol presented to the proximal airway. ${ }^{16}$ However, the clinical response was not different between CPAP nebulization and standard nebulization, and the $\mathrm{FEV}_{1}$ increased similarly with these 2 modalities, which suggests that CPAP may promote aerosol delivery to peripheral airways, and that nebulization during CPAP is effective despite the high flow rate. ${ }^{16}$ In children with cystic fibrosis, PSV increased the lung deposition of a radio-labeled aerosol by about $30 \%$, compared to standard nebulization, without increasing particle impaction in the proximal airways. ${ }^{18}$

A high flow rate may cause deleterious effects related to low humidity of the inspired gas, ${ }^{28,29}$ and optimal humidification may improve comfort and tolerance. ${ }^{30}$ Whereas other studies found a significant increase in particle size and reduced lung deposition with heated humidifier, ${ }^{31,32}$ we found that heat-and-moisture exchanger did not significantly influence aerosol particle size.

\section{Clinical Effects of Nebulization During CPAP}

In several studies the clinical improvement induced by albuterol delivered during CPAP ${ }^{15,16}$ or PSV ${ }^{17,19}$ was similar to or better than that with standard nebulization. A 


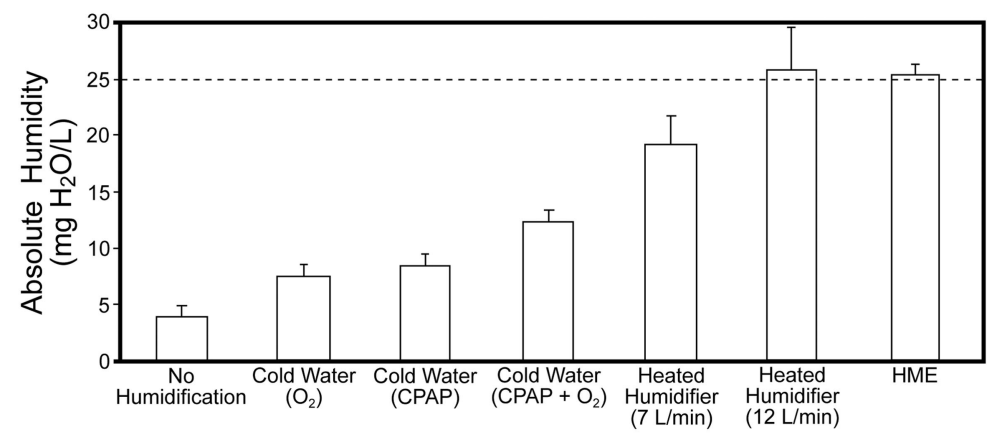

Fig. 4. Absolute humidity during the tested ventilation conditions. Continuous positive airway pressure (CPAP) was driven with dry compressed air. Adequate humidification was provided with heat-and-moisture exchanger (HME) or heated humidifier.

Table 1. Ventilation Variables After Bronchodilator Delivered via Standard Nebulization Versus via Nebulization During Continuous Positive Airway Pressure

\begin{tabular}{|c|c|c|c|c|}
\hline & $\begin{array}{l}\text { Before Standard } \\
\text { Nebulization }\end{array}$ & $\begin{array}{l}\text { After Standard } \\
\text { Nebulization }\end{array}$ & $\begin{array}{l}\text { Before Nebulization } \\
\text { During CPAP }\end{array}$ & $\begin{array}{l}\text { After Nebulization } \\
\text { During CPAP }\end{array}$ \\
\hline Respiratory rate (breaths/min) & $21 \pm 7$ & $16 \pm 4$ & $19 \pm 7$ & $18 \pm 5$ \\
\hline Tidal volume $(\mathrm{mL})$ & $511 \pm 187$ & $590 \pm 243$ & $522 \pm 191$ & $506 \pm 169$ \\
\hline Minute ventilation $(\mathrm{L} / \mathrm{min})$ & $9.5 \pm 2.4$ & $8.7 \pm 2.7$ & $9.5 \pm 4.0$ & $9.1 \pm 3.6$ \\
\hline $\mathrm{P}_{\mathrm{aO}_{2}}(\mathrm{~mm} \mathrm{Hg})$ & ND & $68 \pm 12$ & ND & $80 \pm 15^{*}$ \\
\hline $\mathrm{P}_{\mathrm{aCO}_{2}}(\mathrm{~mm} \mathrm{Hg})$ & ND & $46 \pm 12$ & ND & $45 \pm 11$ \\
\hline \multicolumn{5}{|l|}{ Work of Breathing $(\mathrm{J})$} \\
\hline Per minute & $9.5 \pm 3.4$ & $5.7 \pm 3.6$ & $8.4 \pm 4.2$ & $5.1 \pm 4.2$ \\
\hline Per cycle & $0.5 \pm 0.3$ & $0.4 \pm 0.2$ & $0.5 \pm 0.2$ & $0.4 \pm 0.2$ \\
\hline Per liter & $1.0 \pm 0.2$ & $0.7 \pm 0.3$ & $0.9 \pm 0.2$ & $0.6 \pm 0.4$ \\
\hline Pressure-time product $\left(\mathrm{cm} \mathrm{H}_{2} \mathrm{O} \cdot \mathrm{s} / \mathrm{min}\right)$ & $201 \pm 37$ & $174 \pm 75$ & $205 \pm 64$ & $180 \pm 78$ \\
\hline Intrinsic PEEP $\left(\mathrm{cm} \mathrm{H}_{2} \mathrm{O}\right)$ & $0.8 \pm 0.6$ & $0.6 \pm 0.4$ & $1.0 \pm 1.3$ & $0.7 \pm 0.4$ \\
\hline Heart rate (beats/min) & $86 \pm 13$ & $92 \pm 10$ & $89 \pm 8$ & $93 \pm 19$ \\
\hline Systolic blood pressure (mm Hg) & $139 \pm 25$ & $130 \pm 25$ & $128 \pm 19$ & $131 \pm 24$ \\
\hline \multicolumn{5}{|c|}{$\begin{array}{l}\text { All values are mean } \pm \text { SD. } \\
* \text { Significant difference between continuous positive airway pressure (CPAP) and standard nebulization. } \\
\mathrm{ND}=\text { no data collected }\end{array}$} \\
\hline
\end{tabular}
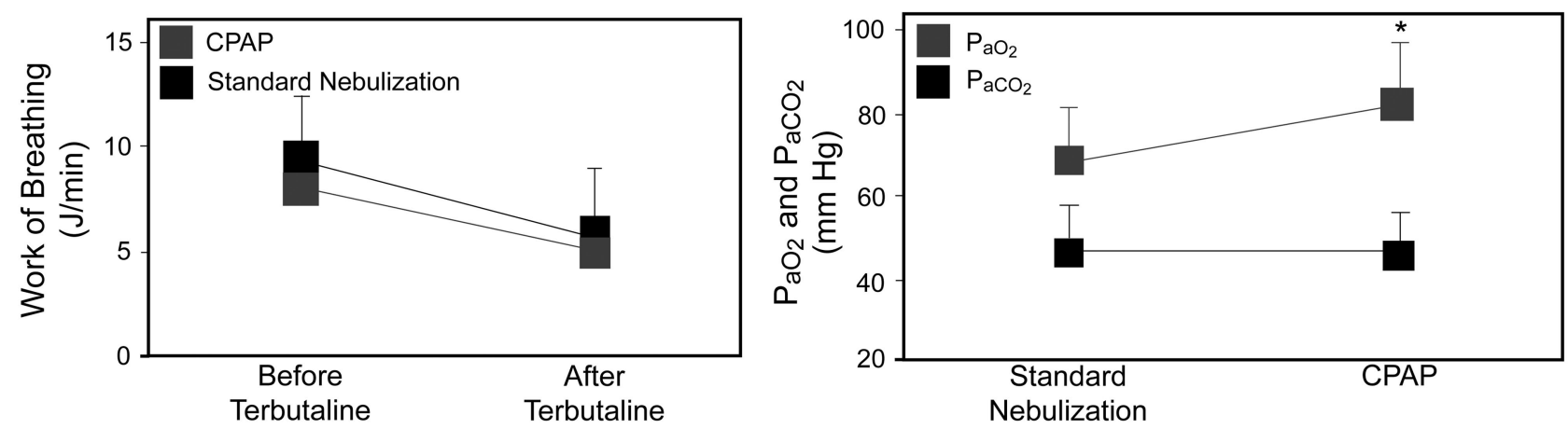

Fig. 5. A: Work of breathing before and after nebulized terbutaline delivered via standard nebulization method versus delivered during continuous positive airway pressure (CPAP). WOB decreased similarly with the 2 methods $(P=.06)$. $\mathrm{B} \mathrm{P}_{\mathrm{aO}_{2}}$ and $\mathrm{P}_{\mathrm{acO}}$ after nebulized terbutaline delivered via standard nebulization method versus delivered during CPAP. $\mathrm{PaO}_{2}$ was significantly higher with CPAP nebulization. $\mathrm{P}_{\mathrm{aCO}}$ was not significantly different between the 2 methods.

randomized trial in patients with acute asthma found greater peak-expiratory-flow improvement when the nebulized albuterol was delivered during PSV with a PEEP of $5 \mathrm{~cm} \mathrm{H}_{2} \mathrm{O}$ $(n=60)$, than with standard nebulization $(n=40) .{ }^{17}$ Another study found an increase in peak expiratory flow when PEEP was added to terbutaline inhalation from a 


\section{Aerosol Delivery and Humidification With the Boussignac CPAP Device}

cone spacer in 10 stable asthma patients. ${ }^{15}$ In 18 stable COPD patients, PSV during nebulized albuterol via spacer proved feasible, and the bronchodilator effect was significant, compared to placebo, although possibly slightly smaller than without PSV. ${ }^{19}$ Although we did not perform spirometry, we found similar trends toward decreased patient WOB with terbutaline nebulized during CPAP and with standard nebulization.

Effects on Work of Breathing and Oxygenation. Nebulization of bronchodilators is a crucial component of the treatment of COPD exacerbation. Benefits may occur despite an absence of spirometric improvement. Thus, in patients with nonreversible airway obstruction (defined as little or no change in $\mathrm{FEV}_{1}$ ), nebulized bronchodilator decreases WOB, dynamic hyperinflation, and dyspnea. ${ }^{33}$ We found a nearly significant decrease in WOB after $\beta_{2}$-agonist nebulization, although dynamic hyperinflation did not decrease significantly, probably because our patients had little intrinsic PEEP and the number of patients was small. A study of intubated patients found that bronchodilator inhalation decreased patient WOB by lowering airway resistance, but without changing intrinsic PEEP, breathing pattern, or arterial blood gas levels. ${ }^{34} \mathrm{CPAP}$ decreases the inspiratory WOB and feeling of breathlessness in patients with severe COPD and acute respiratory failure, during weaning from mechanical ventilation, ${ }^{6-8}$ and during NIV for COPD exacerbation. ${ }^{4,5}$ External PEEP or CPAP decreases the patient's inspiratory effort by counterbalancing the intrinsic PEEP, although the pressure level should be set at a value lower than the intrinsic PEEP to avoid increasing the hyperinflation. ${ }^{35} \mathrm{We}$ found that nebulization with CPAP significantly improved oxygenation, compared to standard nebulization, at the same oxygen flow rate. This effect may be ascribable to PEEP-induced alveolar recruitment or to improved ventilation-perfusion matching.

\section{Limitations}

Our ICU patients were unable to perform reliable spirometry, so we measured WOB in these patients who had a high potential for dynamic hyperinflation and intrinsic PEEP. The main limitation of the clinical part of our study is the small number of patients, which makes it close to a feasibility study and which probably explains that the decrease in WOB after nebulization fell slightly short of statistical significance. However, the WOB decrease was similar with the 2 modalities.

We cannot exclude the possibility that the high flow in the CPAP device increased aerosol particle impaction in the mask. Studies of aerosol delivery in healthy volunteers found that NIV did not increase lung deposition. ${ }^{36-38}$ Of the few studies involving direct lung-deposition measurements in patients, one found decreased lung deposition during NIV, compared to quiet breathing in patients with airway obstruction, ${ }^{39}$ but 2 others, in patients with cystic fibrosis, found greater distal lung deposition. ${ }^{18,40}$

\section{Clinical Implications}

In hypoxemic patients, nebulization during CPAP may eliminate the risk of drop in oxygenation, as can occur when CPAP is withdrawn during standard nebulization. Bronchodilator nebulization with the Boussignac CPAP device is simple and seems clinically effective to deliver $\beta_{2}$-agonist aerosol. Heat-and-moisture exchanger did not influence particle size in our study. A humidification device should be placed between the nebulizer and the Boussignac CPAP device, because the high-flow dry gas during CPAP can dry the airways and increase airway resistance ${ }^{28}$ and cause major discomfort. ${ }^{29}$

\section{Conclusions}

Delivery of aerosolized $\beta_{2}$-agonist bronchodilator was as effective during Boussignac CPAP as during standard nebulization, and the aerosol was not significantly affected by heat-and-moisture exchanger. The WOB decrease was similar with or without CPAP, but CPAP improved oxygenation in a small group of hypercapnic patients.

\section{REFERENCES}

1. Bersten AD, Holt AW, Vedig AE, Skowronski GA, Baggoley CJ. Treatment of severe cardiogenic pulmonary edema with continuous positive airway pressure delivered by face mask. N Engl J Med 1991;325(26):1825-1830.

2. Masip J, Roque M, Sanchez B, Fernandez R, Subirana M, Exposito JA. Noninvasive ventilation in acute cardiogenic pulmonary edema: systematic review and meta-analysis. JAMA 2005;294(24):3124-3130.

3. Squadrone V, Coha M, Cerutti E, Schellino MM, Biolino P, Occella $\mathrm{P}$, et al. Continuous positive airway pressure for treatment of postoperative hypoxemia: a randomized controlled trial. JAMA 2005; 293(5):589-595.

4. Appendini L, Patessio A, Zanaboni S, Carone M, Gukov B, Donner CF, et al. Physiologic effects of positive end-expiratory pressure and mask pressure support during exacerbations of chronic obstructive pulmonary disease. Am J Respir Crit Care Med 1994;149(5):1069-1076.

5. O'Donoghue FJ, Catcheside PG, Jordan AS, Bersten AD, McEvoy RD. Effect of CPAP on intrinsic PEEP, inspiratory effort, and lung volume in severe stable COPD. Thorax 2002;57(6):533-539.

6. Smith TC, Marini JJ. Impact of PEEP on lung mechanics and work of breathing in severe airflow obstruction. J Appl Physiol 1988; 65(4):1488-1499.

7. Petrof BJ, Legare M, Goldberg P, Milic-Emili J, Gottfried SB. Continuous positive airway pressure reduces work of breathing and dyspnea during weaning from mechanical ventilation in severe chronic obstructive pulmonary disease. Am Rev Respir Dis 1990;141(2):281-289.

8. Mancebo J, Albaladejo P, Touchard D, Bak E, Subirana M, Lemaire F, et al. Airway occlusion pressure to titrate positive end-expiratory pressure in patients with dynamic hyperinflation. Anesthesiology 2000;93(1):81-90.

9. Moritz F, Brousse B, Gellee B, Chajara A, L'Her E, Hellot MF, et al. Continuous positive airway pressure versus bilevel noninvasive ventilation in acute cardiogenic pulmonary edema: a randomized multicenter trial. Ann Emerg Med 2007;50(6):666-675, e661.

10. O'Driscoll BR, Taylor RJ, Horsley MG, Chambers DK, Bernstein A. Nebulised salbutamol with and without ipratropium bromide in acute airflow obstruction. Lancet 1989;1(8652):1418-1420. 


\section{Aerosol Delivery and Humidification With the Boussignac CPAP Device}

11. Rodrigo GJ, Rodrigo C. First-line therapy for adult patients with acute asthma receiving a multiple-dose protocol of ipratropium bromide plus albuterol in the emergency department. Am J Respir Crit Care Med 2000;161(6):1862-1868.

12. Clay MM, Pavia D, Newman SP, Lennard-Jones T, Clarke SW. Assessment of jet nebulisers for lung aerosol therapy. Lancet 1983; 2(8350):592-594.

13. Newman KB, Milne S, Hamilton C, Hall K. A comparison of albuterol administered by metered-dose inhaler and spacer with albuterol by nebulizer in adults presenting to an urban emergency department with acute asthma. Chest 2002;121(4):1036-1041.

14. Salmeron S, Brochard L, Mal H, Tenaillon A, Henry-Amar M, Renon $\mathrm{D}$, et al. Nebulized versus intravenous albuterol in hypercapnic acute asthma. A multicenter, double-blind, randomized study. Am J Respir Crit Care Med 1994;149(6):1466-1470.

15. Frischknecht-Christensen E, Norregaard O, Dahl R. Treatment of bronchial asthma with terbutaline inhaled by conespacer combined with positive expiratory pressure mask. Chest 1991;100(2):317-321.

16. Parkes SN, Bersten AD. Aerosol kinetics and bronchodilator efficacy during continuous positive airway pressure delivered by face mask. Thorax 1997;52(2):171-175.

17. Pollack CV Jr, Fleisch KB, Dowsey K. Treatment of acute bronchospasm with beta-adrenergic agonist aerosols delivered by a nasal bilevel positive airway pressure circuit. Ann Emerg Med 1995;26(5): 552-557.

18. Fauroux B, Itti E, Pigeot J, Isabey D, Meignan M, Ferry G, et al Optimization of aerosol deposition by pressure support in children with cystic fibrosis: an experimental and clinical study. Am J Respir Crit Care Med 2000;162(6):2265-2271.

19. Nava S, Karakurt S, Rampulla C, Braschi A, Fanfulla F. Salbutamol delivery during non-invasive mechanical ventilation in patients with chronic obstructive pulmonary disease: a randomized, controlled study. Intensive Care Med 2001;27(10):1627-1635.

20. Chatmongkolchart S, Schettino GP, Dillman C, Kacmarek RM, Hess DR. In vitro evaluation of aerosol bronchodilator delivery during noninvasive positive pressure ventilation: effect of ventilator settings and nebulizer position. Crit Care Med 2002;30(11):2515-2519.

21. Ricard JD, Le Miere E, Markowicz P, Lasry S, Saumon G, Djedaini $\mathrm{K}$, et al. Efficiency and safety of mechanical ventilation with a heat and moisture exchanger changed only once a week. Am J Respir Crit Care Med 2000;161(1):104-109.

22. Derom E, Borgstrom L, Van Schoor J, Lofroos AB, Pauwels R. Lung deposition and protective effect of terbutaline delivered from pressurized metered-dose inhalers and the Turbuhaler in asthmatic individuals. Am J Respir Crit Care Med 2001;164(8 Pt 1):1398-1402.

23. Baydur A, Behrakis PK, Zin WA, Jaeger M, Milic-Emili J. A simple method for assessing the validity of the esophageal balloon technique. Am Rev Respir Dis 1982;126(5):788-791.

24. Sassoon CS, Light RW, Lodia R, Sieck GC, Mahutte CK. Pressuretime product during continuous positive airway pressure, pressure support ventilation, and T-piece during weaning from mechanical ventilation. Am Rev Respir Dis 1991;143(3):469-475.

25. Pepe PE, Marini JJ. Occult positive end-expiratory pressure in mechanically ventilated patients with airflow obstruction: the auto-PEEP effect. Am Rev Respir Dis 1982;126(1):166-170.
26. Lessard MR, Lofaso F, Brochard L. Expiratory muscle activity increases intrinsic positive end-expiratory pressure independently of dynamic hyperinflation in mechanically ventilated patients. Am J Respir Crit Care Med 1995;151(2 Pt 1):562-569.

27. Clay MM, Pavia D, Newman SP, Clarke SW. Factors influencing the size distribution of aerosols from jet nebulisers. Thorax 1983;38(10): 755-759.

28. Richards GN, Cistulli PA, Ungar RG, Berthon-Jones M, Sullivan CE. Mouth leak with nasal continuous positive airway pressure increases nasal airway resistance. Am J Respir Crit Care Med 1996; 154(1):182-186.

29. Lellouche F, Maggiore SM, Lyazidi A, Deye N, Taille S, Brochard L. Water content of delivered gases during non-invasive ventilation in healthy subjects. Intensive Care Med 2009;35(6):987-995.

30. Chanques G, Constantin JM, Sauter M, Jung B, Sebbane M, Verzilli D, et al. Discomfort associated with underhumidified high-flow oxygen therapy in critically ill patients. Intensive Care Med 2009; 35(6):996-1003.

31. Miller DD, Amin MM, Palmer LB, Shah AR, Smaldone GC. Aerosol delivery and modern mechanical ventilation: in vitro/in vivo evaluation. Am J Respir Crit Care Med 2003;168(10):1205-1209.

32. Ari A, Areabi H, Fink JB. Evaluation of aerosol generator devices at 3 locations in humidified and non-humidified circuits during adult mechanical ventilation. Respir Care;55(7):837-844

33. Man WD, Mustfa N, Nikoletou D, Kaul S, Hart N, Rafferty GF, et al. Effect of salmeterol on respiratory muscle activity during exercise in poorly reversible COPD. Thorax 2004:59(6):471-476.

34. Mancebo J, Amaro P, Lorino H, Lemaire F, Harf A, Brochard L. Effects of albuterol inhalation on the work of breathing during weaning from mechanical ventilation. Am Rev Respir Dis 1991;144(1): 95-100.

35. Ranieri VM, Giuliani R, Cinnella G, Pesce C, Brienza N, Ippolito $\mathrm{EL}$, et al. Physiologic effects of positive end-expiratory pressure in patients with chronic obstructive pulmonary disease during acute ventilatory failure and controlled mechanical ventilation. Am Rev Respir Dis 1993;147(1):5-13.

36. Franca EE, Dornelas de Andrade AF, Cabral G, Almeida Filho P, Silva KC, Galindo Filho VC, et al. Nebulization associated with bi-level noninvasive ventilation: analysis of pulmonary radioaerosol deposition. Respir Med 2006;100(4):721-728.

37. Reychler G, Keyeux A, Cremers C, Veriter C, Rodenstein DO, Liistro G. Comparison of lung deposition in two types of nebulization: intrapulmonary percussive ventilation vs jet nebulization. Chest 2004; 125(2):502-508.

38. Reychler G, Leal T, Roeseler J, Thys F, Delvau N, Liistro G. Effect of continuous positive airway pressure combined to nebulization on lung deposition measured by urinary excretion of amikacin. Respir Med 2007;101(10):2051-2055.

39. Dolovich MB, Killian D, Wolff RK, Obminski G, Newhouse MT. Pulmonary aerosol deposition in chronic bronchitis: intermittent positive pressure breathing versus quiet breathing. Am Rev Respir Dis 1977;115(3):397-402.

40. Laube BL, Geller DE, Lin TC, Dalby RN, Diener-West M, Zeitlin PL. Positive expiratory pressure changes aerosol distribution in patients with cystic fibrosis. Respir Care 2005;50(11):14381444.

This article is approved for Continuing Respiratory Care Educatior credit. For information and to obtain your $\mathrm{CRCE}$

(free to AARC members) visit www.RCJournal.com

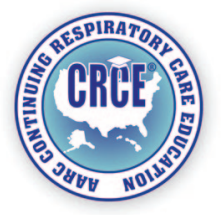

